\title{
The Politics of Sexuality and Sport
}

\section{Introduction}

Annually I teach a group of final year under-graduate physical education students about issues related to sexuality and sport. The lecture starts with the students traditionally being asked to mention the first things that come to their minds when they think about lesbians and gay men and sport. After some initial trepidation, students consistently comment gay men like individual or 'feminine' sports like swimming or dance, while they perceive a lot of lesbians take part in soccer, field hockey or rugby. Normally these stereotypes generate quite a bit of laughter in the room. Further, after presenting them the history of the global growth of gay sport networks, one female student stated recently “I don't understand the big deal. Everyone gets along and young people here don't care if you're gay or straight. I don't understand why there is a need for gay sport clubs or the Gay Games...people should just openly play in a club or in the Olympics.” While this may indicate what McCormack (2012) considers as diminished cultural homophobia, the student demonstrates naiveté regarding the complex nature and politics surrounding sexuality and sport. She may not be considering her place of study being privileged. Her University and department, teaching physical education, which has a long history of feminism and being tolerant of sexualities, is located in the south of England, near a city (Brighton) known for being liberal and gay-friendly. Therefore her world view is biased, insulated perhaps by her environment (academia), and does not consider a perspective from more conservative parts of the country. This would include, for example, the debated challenges associated with being 'out' in rural areas or less developed nations (see Leedy and Connolly 2007: Weinke and Hill 2013). Additionally, she and her fellow colleagues had difficulty in identifying famous gay athletes, further showing considerable work remains to be done despite her comments that people should play openly, regardless of sexuality. Further, as highlighted later, recent developments regarding (homo)sexuality and mainstream sport have attracted some significant (sport) media attention. Thus, this provides an opportune time to re-visit the topic of sexuality and sport and delve into some current and key, but not exhaustive, political and ideological tensions associated with lesbian and gay sport.

In addition to a review of the literature and theoretical debates associated with sexuality and sport, this chapter is underpinned by a qualitative approach. A number of interviews were carried out with stakeholders at the most recent 2014 Gay Games in Cleveland/Akron. The author's experience and research at four past Gay Games (Sydney, Chicago, Cologne and Cleveland/Akron), and considerable sport participation in both grassroots straight and gay clubs in Canada and the United Kingdom, helps provide a critical insight into some current political issues. Some may consider this insider view as 
subjective and potentially a source of bias; however, I argue this approach provided an in-depth understanding into key political issues.

While major themes related to the sociological and cultural analysis of modern sport have long focused on issues of gender, race, and class, only more recently since the 1990s has the topic of sexuality and sport strongly emerged (see for example Caudwell 2006; Connell 1990; Messner 1992; Pronger 1990; Theberge 1995). Like gender scholars, most sexuality researchers consider sexualities as ongoing and fluid constructions rather than stable identities around which action is organized (Butler 1990; Laurendeau 2004). Hence this chapter interchanges and uses various terms to be inclusive of a range of sexual identities. The term gay is employed at times to encompass lesbians, gay men, bisexuals, transgendered persons, queer, questioning and/or intersex (LGBTQI). Many sport clubs around the globe simply use the term gay, whilst others incorporate lesbian/gay in their name to identify they are catering to sexual minorities.

Sexuality and sport falls under the wider analytical area of gender issues because sport is one of the cultural spheres that most explicitly generates, reproduces and publicly displays gender identities and difference, and justifies the existing hierarchical gender order (Connell 1995; McKay et al. 2000; Theberge 2000). Indeed, sport appears to be historically slower than other areas in society, like the workplace, politics, and the military/police in welcoming or addressing issues related to women and/or LGBTQI persons. More on how the generally conservative sporting arenas attempt to preserve a masculine space is discussed later; however, it is initially important to keep in mind that gender and sexuality clearly intersect. The historical roots of gay sport and recent popular media accounts of (homo)sexuality and sport are first discussed to set the scene before some key theoretical implications are reviewed and debated.

\section{Historical Roots of Gay/LGBTQI sport}

Formal organized gay sport clubs, networks and related events are a fairly recent global phenomenon. Messner (1992) noted since the outset of the gay liberation movement in the early 1970s, sport has become an integral part of the growth of lesbian and gay communities. As gay men and lesbians emerged from underground bars and other covert sites in Western industrialized nations, sport became a new place where they could be more visible and socialize. Thus, gay athletes began an appropriation of spaces (Williams 1961), playing sport in public parks and venues, which were traditionally occupied by mainstream sporting groups and an ideology that favours and promotes heterosexuality (Krane 2001; Wright and Clarke 1999).

Lesbian and gay men in the 1970s began to organize clubs because mainstream sports were not comfortable spaces for them. With the establishment of gay sports leagues in many cities across North America (largely centred on softball, volleyball, tennis, bowling and swimming) and in Europe 
(mainly volleyball, tennis, badminton, soccer and swimming) the founders began to form annual tournaments that attracted teams from many places. The need to arrange and administer these national and international sporting events required further coordination, and thus many formal sport associations were established during the late 1970s and 1980s. These included the North American Gay Amateur Athletic Alliance (established 1977), the San Francisco Arts \& Athletic (1981), which eventually became the Federation of Gay Games (FGG) (1989), which manages the Gay Games movement, and the European Gay and Lesbian Sport Federation (1989), responsible for the EuroGames. Thus organized gay sport occurs within an increasingly sophisticated network of individuals, teams, and leagues operating on local, national and/or international levels. For example, the Gay and Lesbian Tennis Alliance (2014), founded in 1991, has grown into a global group that has around 10,000 members with some 70 tournaments per year in cities like Bangkok, Dallas, Katowice, Denpasar and Rome.

Since gay men and lesbians tend to migrate to urban areas, the vast majority of their sport involvement takes place in cities. Most larger cities in Europe, North America, Japan, and Australia tend to have some type of visible gay sporting group. Although a vast array of organized sporting opportunities exist, it is important to recognize that there are obviously LGBTQI persons who participate in sport outside the formalized gay sport networks. A cursory internet review reveals an array of opportunities, with clubs offering golf, running/walking, surfing, darts, snowboarding, basketball, sailing, rodeo, dancing, ice hockey, curling and wrestling. Since the millennium the growth and visibility of gay sport clubs and events has moved beyond the more developed nations to cities in developing countries such as Buenos Aires, Mexico City and Cape Town. These places, not traditionally known as gay friendly, are fast attracting local residents as well as international gay sport tourists as societal attitudes change. For example, the BBC (2012) reported Kathmandu, Nepal hosted South Asia’s first gay sports tournament in 2012 with more than 300 participants from 30 countries.

The Gay Games, held every four years like the Olympics, is arguably the most popular and recognized sport event for the LGBTQI community. The mission of the FGG (2014a), much like any gay sport group, is "to promote equality through the organization of the premiere international LGBT and gayfriendly sports and cultural event known as the Gay Games. They are built upon the principles of participation, inclusion and personal best.” Gay sports groups have gone out of their way to stress inclusiveness, regardless of skill, age, gender, disability, race, class, HIV status, geographic origin and sexual orientation. Less known is that straight athletes and allies can also participate in the event, a phenomenon known as ‘inverse integration’ (Elling et al. 2003).

A political conflict has emerged as it appears the Gay Games stress friendship over the sexuality of the event. Thus this could be seen as the erasure of lesbian and gay difference in the pursuit of sporting legitimation as Pronger (2000: 232) argued "gay sports proves the normality of lesbians and 
gay men.” While he believes gay sport groups are inclusive of gay identities, he is critical because they are attempting to remove homosexuality and sexual desire from the discussion. Miller (2001) disagrees and contends sports are clearly undergoing immense change with sex at the centre.

The opening and closing ceremonies of the Games are highly political events, with increasingly prominent celebrities and politicians taking part, reminding athletes of past and present struggles. The 2014 Cleveland/Akron opening ceremonies included a 90 second video from President Barack Obama, enthusiastically cheered by the audience. Obama said,

...we have come a long way in our commitment to the equal rights of LGBT people here and around the world. I am proud of my administration's record and of the citizens who've helped to push for justice. I know some of you have come from places where it requires courage, even defiance to come out, sometimes at great personal risk. You should know the United States stands with you and for your human rights, just as our athletes stand with you on the field at these Games...

Athletes can also apply for financial support, as part of the FGG's human rights campaign, to help subsidize the cost of travelling to and taking part in the Games. They have been granted to athletes coming from developing nations in Africa, Asia and South America, as well as parts of Eastern Europe. Many of these athletes become activists and travel back to their own host nations to further promote the development of gay sport. Some Russian athletes were honoured by the FGG to travel and participate in the 2014 Cleveland/Akron Gay Games, to highlight the oppression of gay rights under the leadership of Vladimir Putin.

Athlete figures at gay competitions tend to vary by source and can be disputed. According to the FGG (2014b) the number of participants in the Gay Games has grown from an initial 1,300 athletes in San Francisco in 1982 to a peak of 13,000 in Amsterdam in 1998. Cologne attracted 10,000 in 2010, whereas just under 8,000 attended Cleveland/Akron in 2014. Critics may point to this as a diminished demand although there are some more simple explanations for the declining numbers. Cleveland/Akron, may possess less tourism appeal among potential participants within the U.S. and globally (Gilbert 2014) compared to previous host cities like New York or Vancouver. However, further scrutiny reveals some more complex political issues at play. There was a split within the Gay Games movement with the awarding of the event to Montréal in 2006. The Federation pulled support for the Canadian hosts over concerns about the size and lack of financial transparency and gave Chicago the Games (Jarvis 2013a). From the ashes of Montréal a new global gay sport event emerged, namely the World/OutGames, overseen by the Gay and Lesbian International Sport Association. This spread and diluted the demand for an iconic global event as more were occurring not just every four years. There have been discussions to reconcile the schism between the two 
competing groups to pave the way forward for one global unified games; however, at the time of writing recent talks failed. Participation numbers from previous World OutGames in Montréal, Copenhagen and Antwerp are difficult to verify although The Guardian (2009) claimed 5,500 attended the Danish event in 2009.

In addition to the multitude of annual local sport festivals, traveling to compete in multi-day events is expensive and many gay athletes, especially women, those from ethnic minorities or developing nations, find it difficult to take part. Executive Director Phyllis Harris (2014) of the LGBT Community Center of Greater Cleveland expressed concern about the lack of African-American, Hispanic and youth participants in the Games. Indeed, much like the mainstream arena (King et al. 2007; Theberge 2000), the organization and participation of gay sport tends to be dominated by a privileged white male middle class (Davidson 2013). Recent Games numbers are likely to have been affected by the global financial crisis and recession (2007-12). A litmus test may be seen at the next Gay Games, which are to take place in Paris in 2018. The French organizers plan to attract 15,000, which would make it the largest gay sport event ever. Certainly its geographic position, high tourist amenities and appealing sport venues, such as Roland Garros for tennis, may make the targeted number achievable, as participants choose this event over others on the gay sporting calendar.

Many of the sports participated in by lesbian and gay athletes reflect what Messner (1992) and Pronger (2000) identify as a value system and vision based on feminist and gay liberationist ideals of equality and universal participation. This is defined by allowing a range of people to participate, regardless of sexuality and/or skill level. Sport for gay people is seen as part of a general celebration and display of gay culture with a marked focus on making conspicuous lifestyle statements (Hargreaves 2000). They also constitute a powerful and public reaction to homophobic discrimination and oppression in sport, and provide a safe space for participants. On this level then, participation in gay sport can be seen as having emancipatory power. The global growth and development of gay sports networks and events, like the Gay Games, have transformed the way gay athletes experience and understand sport (Pronger 2000; Symons 2010). While this paints a positive picture and signifies progress for sexual minorities in the arena of physical activity, there exists a series of issues with wider implications that have accompanied the development.

The Gay Games/OutGames and smaller tournaments may be significant and meaningful for those that take part, in addition to the considerable economic and tourism impacts for the destinations, but they gain little attention from the wider national and global mainstream media. Some television reporting was noted on local stations where Gay Games have taken place. Major newspapers in host cities, such as the Sydney Morning Herald, Chicago Tribune, Kölner Stadt-Anzeiger, and Cleveland Plain Dealer, devoted extensive daily front page news coverage of the Gay Games, but significantly 
only in the news section, and not in the sports pages. Whether this helps validate or undermine the legitimacy of the event as a sport spectacle is worthy of future scrutiny.

Much of gay sport, especially at the grassroots level, tends to take place away from the public gaze. Whether this represents a local gay tennis club playing on some courts, badminton in an indoor community centre, or softball teams competing on a diamond in a public park, few people walking by would likely stop to notice LGBTQI persons playing sport. Certainly larger events, like the Gay Games, receive some local media attention, but how challenging can they be if wider society is limited in their awareness? Messner (1992) suggested the Gay Games represent a radical break from past conceptions of the role of sport in society, they do not represent a major challenge to sport as an institution. This is because they still do not necessarily confront or change the dominant structure of sport because they largely occur in spaces outside of the dominant mainstream settings. Hargreaves (2000) furthered this point by observing gay sport tends to take place in insular ghettoized spaces and that gay sports liberation is partial and conditional - it has only come with separation and not with integration. The contestation and clash around space and meaning, and the aspiration to provide space for new types and different forms of sporting cultural expression, such as the OutGames and Gay Games, is a key issue. Thus while opening and closing ceremonies of the Gay Games held in public hypermasculine spaces like Soldier Field, home of the National Football League's Chicago Bears, Amsterdam Arena (Ajax football club), or Quicken Loans Arena, (National Basketball Association's Cleveland Cavaliers), can be seen as somewhat challenging, it is not until these events and their political ambitions become even more widely reported among more (sporting) media outlets, will gay sport further challenge traditionally conservative sport institutions.

However, some noteworthy movements and integration between mainstream and the gay sporting spaces offers some potential. The traditional locations of where LGBTQI athletes can take part is seen conceptually as in binary opposition - see Figure 1 (modified from Jarvis 2013b). The more conservative mainstream sites are considered as professional leagues, schools, adult/youth voluntary, private and grassroots clubs. Here, it is assumed the vast majority of participants are heterosexual although closeted or openly gay athletes may also take part. According to Jarvis (2006) some gay women and men leave mainstream sport sites for a multitude of reasons, move into gay sport clubs, and remain for the rest of their sporting careers. This is represented by a smaller circle because of the fact there are less of them available compared to mainstream spaces.

Figure 1

The Binary of Mainstream and Gay Sport Space 


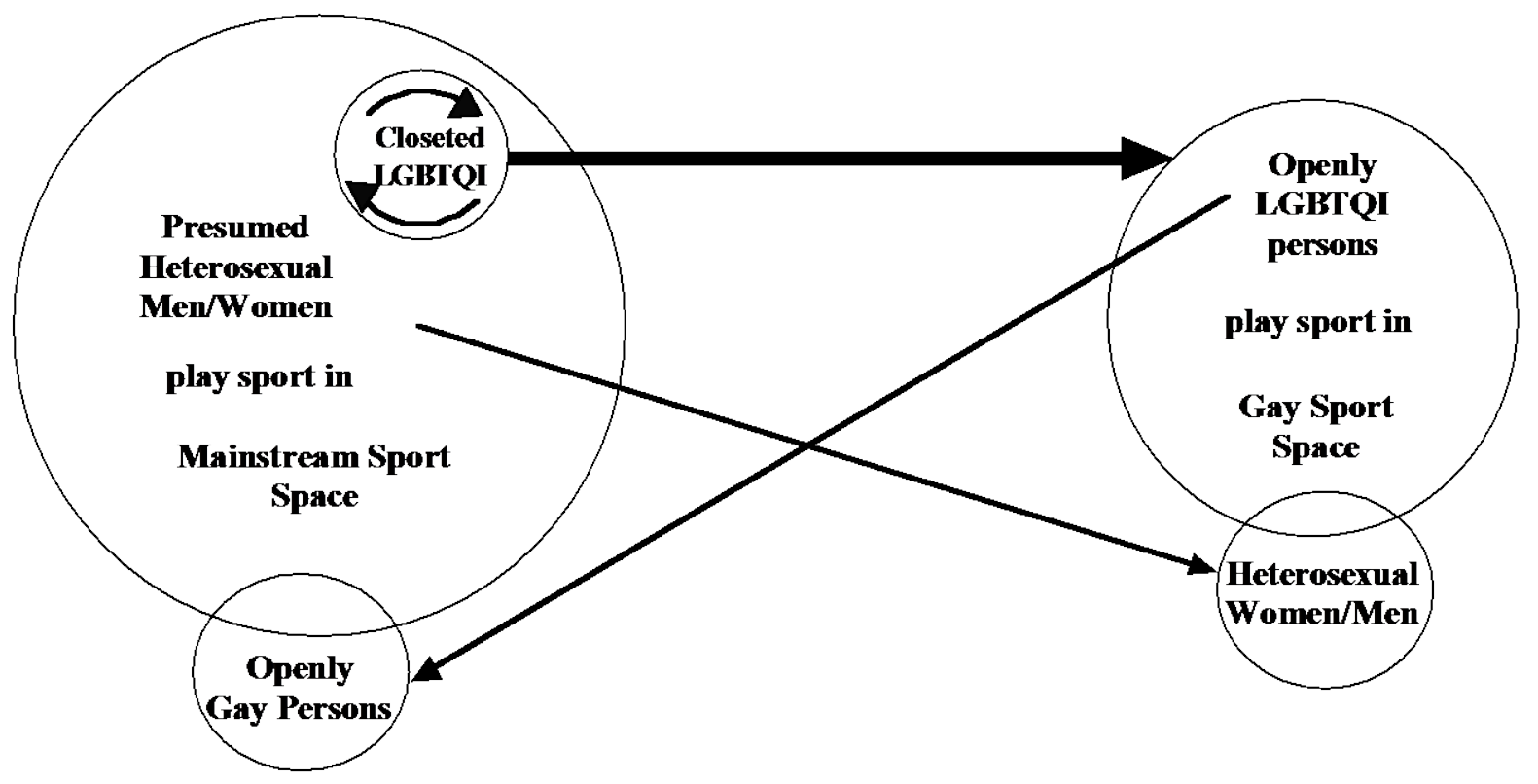

Elling et al. (2003) and Wellard (2002) argue the reality of gay sport clubs can be full of tensions and contradictions. On one hand they are created to offer a setting away from the oppressive compulsory heterosexuality in mainstream sites; on the other, they tend to be based on conventional sporting values that promote competition and winning. Some gay athletes may gain sporting capital within these sites and progress back into mainstream sites and participate openly as gay. The Brighton gay tennis club in England openly competes within the mainstream parks league and is accepted regardless of sexuality. Many gay clubs like rowing or curling also compete directly with straight mainstream clubs simply because of the lack of numbers and/or competition. To add complexity and fluidity to the model, some heterosexual men and women move from mainstream spaces into gay clubs, for example because of siblings or friends, or a lack of available offerings (Jarvis 2013b), previously noted as reverse integration (Elling et al. 2003). Thus the traditional binary is becoming more blurred. This does offer some further political intrigue. While some critics (Davidson 2014; Pronger 2000) may argue gay sport is not challenging traditional dominant notions of sport, the increasing transgressive movement of athletes, regardless of sexuality, between the two binaries, mainly at the grassroots level, but also within elite and professional sites, shows some opportunity to break down the conservative nature of sport as an institution. The next section continues with other disruptive developments related to popular media accounts of the contested integration and prominence around sexuality and sport discourse.

\section{The Political Implications of Sexuality and Sport Accounts in the Media}

Recent developments regarding (homo)sexuality and mainstream sport have attracted some significant media attention. There are strong reasons why academics should now pay attention to 
how traditional mainstream and increasingly web-based and social media talk about sport, including that it is inescapable and mediasport's global reach means messages reach billions of people (Bruce 2012). Earlier media accounts of gay athletes were reported generally in a negative fashion, such as the ‘tragic' life of English professional football player Justin Fashanu, who hung himself in 1998 after being accused of sexually assaulting a 17 year old youth in the U.S.A. The tabloids, and especially the (black) football media, were particularly harsh (see Caudwell 2011). However, more positive perspectives are now commonly provided. The Sporting News (2014) reported the Women's National Basketball Association became the first professional sports league to specifically recruit gay fans to its games. Various sport media outlets and official team websites show a number of professional franchises in the U.S. and Canada now host 'pride events' for LGBT people, recognizing their diverse fan base. Some may argue this is simply a marketing exercise to fill empty seats.

The 'It Gets Better Project', an anti-bullying campaign created by syndicated columnist and author Dan Savage in the U.S., attracted many high profile professional teams and athletes to video post their support for LGBT youth. High profile professional (and self-identified heterosexual) athletes have become political allies, supporting gay rights and equality, not only within sport spheres, but also related to wider societal issues such as gay bullying and same sex marriage. Griffin (2011) comments these developments seem like progress although she states "more is required of straight 'allies' in the campaign against homophobia and discrimination toward the LGBT community.”

The former German footballer Thomas Hitzlsperger came out in 2014, which attracted significant news attention in Germany, and the U.K. Chancellor Angela Merkel's spokesperson praised the news as reported in mainstream sources like Die Zeit (Caspari and Fritsch 2014). Previous athletes, like former National Basketball Association (NBA) player John Amaechi in 2007, have typically revealed their sexuality after their playing careers were finished, because they reveal it likely would have affected their earning potential. However, Hitzlsperger stated "for me it would have been almost impossible had I still been playing - not because of the fans or the other players, but because of the media” (Gallagher 2014). Australian swimmer and Olympic medallist Ian Thorpe, who finally came out in 2014 at the age of 31 on a popular television show, indicated he wanted to as early as the year 2000 but was warned of the financial consequences (McClymont and Bagshaw 2014). More encouraging are recent developments of current athletes declaring their homosexuality while still in the midst of their careers, albeit some toward the end of their peak. The 'coming outs' of Welsh rugby star Gareth Thomas and Irish Hurler Donál Óg Cusack both in 2009, the English cricketer Steven Davies, and Swedish footballer Anton Hysén both in 2011, and Robbie Rogers, an American soccer player in 2013, were reported in the British media. Orlando Cruz, from Puerto Rico, became the first openly gay and highly ranked professional boxer in 2012. 
The acknowledgement of the NBA's Jason Collins' sexuality in 2013, the first openly active gay player in one of the four major professional leagues in North America, seems to be a watershed moment, generating front page mainstream and sport news coverage. Further, in 2014 Michael Sam became the first openly gay college American football player to be drafted by the National Football League. Both coming outs warranted the prestigious cover story for Sports Illustrated and provide further political intrigue because both athletes are also African-American. Sam's announcement, along with British diver Tom Daley coming out at the age of 19, also in 2014, are significant because they represent young athletes at the start or entering the prime of their careers, with less consideration for loss of potential earnings. Indeed, they may attract additional sponsorship opportunities specifically because they are gay. Nike reportedly wants to sponsor the first prominent professional gay athlete (Anderson-Minshall 2013), perhaps making it lucrative for someone to come out. Indeed mainstream corporate sponsors have increasingly associated themselves with the gay sport movement (Jarvis 2002), although Davidson (2014) is concerned with the commodification of the Gay Games, as some may argue companies may just be trying to market to and exploit niche markets. Either way, attracting wider sponsorship can be seen as helping to legitimize gay sport (Suchman 1995).

For the most part, these coming outs were welcomed by the media, other players and management. Despite this, Kian et al. (2013) state most American based sport journalists are reluctant to report on athlete's non-normative sexual orientation. They further say U.S. sport fans are ready for openly gay players in men's professional team sport but the locker room may be slower to adapt. However, athletes like Daley, Sam and Collins have suffered homophobic abuse on many mainstream sport media blog sites, with many comments asking why these stories are even newsworthy. An initial review of sport fan comments on Sports Illustrated or CBS Sports websites over the past couple of years show negative homophobic remarks far outweigh positive support. This undermines the earlier comments made by some of my students, who were naïve about sexuality and sport not being such a "big deal." This demonstrates there is still considerable progress to be made despite signs of diminished cultural homophobia.

The coming out of male athletes garners considerable media scrutiny, because sport is often viewed as a male, heterosexual and masculine pursuit and space (Allain 2008; Bruce 2012). Females who announce they are lesbian or bisexual merits less spotlight. However, this may also be due to the longstanding underrepresentation of women in the mainstream media (Bernstein 2002; Cooky et al. 2013) and/or their sexuality being less a story, because in certain sports female athletes are expected to be gay (Krane 1996; Lenskyj 1991). While tennis players Martina Navratilova and Billie-Jean King attracted much, somewhat negative, coverage in the 1980s, female athletes who more recently acknowledged their sexuality has been less problematic or 'newsworthy'. A young Amélie Mauresmo came out in 1999 at the start of her tennis career. She did receive initially some negative 
comments from a couple high profile fellow female players although this issue seemed to disappear rather quickly after some apologies. Mauresmo became a popular player among fans, reporters, competitors and sponsors. The more recent announcements of athletes like Casey Stoney, England football captain, Brittney Griner, American basketball player, Ireen Wüst, Dutch Olympic medallist speed skater, and Casey Dellacqua, an Australian tennis player received little attention. These quieter declarations raised some media interest and, along with the media frenzy associated with their male counterparts, serve more importantly as role models for many aspiring young LGBTQI athletes who may be questioning their sexuality, trying to compete at high levels, considering the potential loss of earnings and/or deciding whether to come out to fellow teammates, sponsors, coaches, management or the media.

These collective mainstream accounts indicate some significant positive changes in the attitudes towards homosexuality within the western sporting world, or what Anderson (2009; 2011a; 2011b) considers to be diminished cultural homophobia. Further academic research helps support this trend, not only in wider society (McCormack 2012), but explicitly within sport, and contrary to popular assumptions about embedded negative attitudes toward homosexuality. For example, Adams and Anderson (2012) argue athletes in a small Midwestern Catholic college soccer team were accepting of homosexuality. Cashmore and Cleland's (2012) research on fans and professionals found rapidly decreasing homophobia within the culture of football fandom in the U.K.

However, negative attitudes about homosexuality remain strong in many parts of the world. Russian pole vaulter Yelena Isinbayeva, a gold medal winner in the 2013 World Athletic Championships in Moscow, defended her country's anti-gay propaganda laws, and disapproved of fellow athletes for showing solidarity for lesbians and gay men (Majendie 2013). A clearer example that garnered significant media coverage was the 2014 Winter Olympics held in Sochi, where Russian President Vladimir Putin controversially welcomed gay visitors to the Games but said "they must leave children alone” (Walker 2014). Russia has been criticised for its treatment of LGBT people, along with a number of other human rights issues, with Amnesty International (2014) claiming the legacy of the Sochi Games has been tarnished. Coincidentally several heads of states did not attend the opening ceremonies, likely in a thinly veiled protest, including those from Germany, United Kingdom, France and the United States. Boren (2013) reported President Obama instead sent two openly gay athletes to represent the American delegation, namely tennis legend Billie Jean-King and Caitlin Cahow, a two-time Olympic hockey medallist. This demonstrates the conventional understanding of the relationship between politics of sexuality and sport remains a complex and much contested topic.

\section{Theoretical Frameworks for Understanding Sexuality and Sport}


This final section discusses the key theoretical debates related to sexuality and sport issues. Scholarship has long focused on how sport reproduces, legitimates and occasionally challenges ideologies of gender. Thus it has been framed by diverse methodological and theoretical approaches particularly exploring femininities and masculinities, and how gender is constructed. Sport has traditionally been seen as a mainly male and hegemonically masculine space (Bruce 2012). The aforementioned media accounts are largely written by men, for a male readership. News stories are normally about male athletes, teams owned by men or sporting institutions run by them. Sport, whether mediated or not, therefore tends to marginalize athletes who do not fall within this narrow domain, including women and people from sexual minorities. The notion of power is thus central to the topic of gender and sexuality (in)equality within sport. Women are simply underrepresented in the sporting world, especially within leadership positions (Adriaanse and Claringbould 2014), even more so for lesbians and gay men. Several relevant critical concepts have been used to explore sport and sexuality and gender issues.

Historically, the most common theoretical framework for understanding the hierarchy of masculinities is Connell's concept of hegemonic masculinity (1995). For some academics (Hirose and Pih 2010; Jones and McCarthy 2010), Connell's framework provides a useful tool to theorize gendered power relations among men and understand the effectiveness of masculinities in the legitimation of the gender order within sport. However, this framework has been challenged from several directions in recent years (Anderson 2011a; Beasley 2008; Cashmore and Cleland 2012; Howson 2006; McCormack 2011).

For instance, Anderson (2009) argues hegemonic theory was appropriate in the 1980s and 90s when there were higher levels of homophobia in society, especially within sporting spheres. In times of decreased cultural homophobia, he argues for a rethinking of traditional theories to understand men and their masculinities. Anderson (2011b: 252) argues hegemonic masculinity theory "fails to accurately account for what occurs in a macro or even local culture of decreased cultural homophobia.” Instead, he claims ‘inclusive masculinity’ is a way forward to frame current research because 'multiple masculinities coexist harmoniously, but also fewer behaviours will be associated with homosexuality' (2011b: 254). Inclusive masculinity is a space for less oppressive masculinities to proliferate without social stigma as the hegemonic archetype of conservative masculinity fails to maintain its dominance (Adams and Anderson 2012). Clayton and Harris (2009) refer to the emergence of new types of sporting identities and masculinities, such as the metrosexual athlete like David Beckham. Dashper (2012) draws on inclusive masculinity theory with her research on gay and straight men within equestrian sport, showing low levels of homophobia within once unreceptive locales. 
At a symposium at Sussex University Connell (2014) recently reflected on the origins and critics of her highly influential concept of hegemonic masculinity. She argued in times of economic and social instability, the concept of a gender order does not necessarily work. She suggested hegemonic masculinities are 'under construction', and are trying to stabilise themselves. She welcomed challenges to the idea of hegemonic masculinity, particularly studies exploring masculinities coming from the global peripheries, such as Africa and South America. Her keynote concluded by emphasizing scholars cannot remain in the conceptual world in which the field was constructed, and that methods also need to change in order to examine new configurations of masculinities, and new forms of contestations and transformations. Perhaps there remain possibilities for exploring and understanding masculinities in sport by combining elements of both hegemonic and inclusive masculinity frameworks, as homophobia has not diminished universally. As Caudwell (2011) comments social power relations infuse and suffuse (sport) spaces, and the human body helps construct hegemonic but also counter-hegemonic identities and subjectivities. Beside sport's gender politics are far from being totally dominated by a straight, orthodox masculinity; some athletes are marketed to niche groups, such as heterosexual women and gay men. Connell (2009) contends researchers need to move away from a focus on gender differences to one on relationships between and among women and men, including the personal and institutional.

Queer theory has also been used as a framework in an attempt to critically explore the intersection of sexuality, gender and sport (Caudwell 2006). Queer theory has generally been mobilized in the service of non-normative sexualities and desires to destabilize and contest hegemonic structures, such as heteronormativity (Warner 2004). Therefore it can be considered to be a critical theory, which is about action and political involvement. The strength of queer theory is that it enables identity categories and binaries to be questioned. Caudwell's (2006) edited book shows how researchers documented the experiences of lesbian, gay, transgender and transsexual athletes in sport in an attempt to move beyond traditional sex-gender distinctions found in sport institutions. Broad's (2001) research on women rugby players in the U.S. demonstrated how they destabilized the heterosexual/homosexual binary through resisting gendered norms. Queer theorists such as Davidson (2014) argue traditional conventional sport should be challenged and disrupted. However, queer advocates (Pronger 2000; Sykes 2006) do not offer clear new ways to reconfigure sport once the more conservative aspects are dismantled. Davidson’s (2006) call for the Gay Games to become more radical and 'queer', such as athletes dressing up in wedding outfits and not awarding medals to winners, falls on many deaf ears. Jarvis (2013a) indicated this would not be popular among the athletes that take part, nor the organizers who want to maintain a commercially viable event.

Coming back to gay sport, the question remains as to whether LGBTQI athletes, clubs and global events are resisting or undermining traditional notions of a dominant masculinity when most of the 
play occurs solely within gay leagues and is minimally integrated within mainstream sport. Many gay athletes and clubs are not very political. They do not go out of their way to overtly challenge hegemonic practices found in mainstream sport as many have the same values as competition and winning (Wellard 2002; Jarvis 2006). Indeed the majority of lesbian and gay male participants exhibit many conventional forms of femininity and masculinity found in straight sport spaces. The vast majority of LGBTQI athletes want to show they like sport just like anyone else.

\section{Progressing Sexuality and Sport Research}

The condition of LGBTQI athletes can offer important political insights into the contemporary and generally conservative, albeit evolving, world of sport. This section offers suggestions to progress the knowledge and debates related to political issues associated with sexuality and sport. More information on the stories and experiences among a diverse range of LGBTQI athletes is required, especially from developing nations or global peripheries. This will help extend how sporting femininities and masculinities are understood in an increasingly global world as these constructs tend to be dominated by western orthodoxy. In-depth ethnographic approaches are needed to provide detailed accounts of the lived experiences of gay athletes at either the elite or grassroots level. This is especially important within mainstream settings as this will potentially offer more chances to challenge or disrupt conservative sporting institutions. These insights can allow the chance to reinterpret the athletic experience in ways that offer the potential to transform the heterosexist/heteronormative culture of sport. Does their participation allow for the possibility of new embodied masculine/feminine identification to emerge, not only among themselves but their fellow heterosexual colleagues? More data are needed on the transgressive movements of athletes crossing the increasingly blurred binary of mainstream and gay sport spaces.

The popular media accounts of gay athletes offers some exciting avenues. Does the (lack of) coverage help validate or undermine the legitimacy of gay sport events? Further, how does the television, print or social media contribute to undermining or maintaining the traditionally conservative masculine nature of sport as an institution? Do the stories of high profile athletes help other elite or grassroots participants to acknowledge their own sexuality? The attraction and/or commodification of gay athletes or events by mainstream sponsors, and links again to legitimacy, are also worthy of more scrutiny.

It is crucial to continue to explore how contemporary forms of mainstream and/or LGBTQI sport reproduce or challenge traditional dominant notions of masculinity and femininity. What social conditions underlie this and enable it to occur? More empirical data are required to conceptualize how LGBTQI sport can potentially offer resistance to traditional hegemonic masculinity much in the way past feminist research on women and sport has explored and debated the same issue. Inclusive 
masculinity theory is an exciting development; however, more research is needed to support whether all types of sport sites are indeed evolving and changing for the better all around the world. Certainly there is diminished cultural homophobia but this is not occurring at the same rate universally.

Gay sport provides opportunities for queer resistance, but this can also lead to increased opposition by the wider public instead of greater acceptance of the gay community. Some gay participants themselves are not very political and do not agree with the radical politics of queer, which calls for the dismantling of existing sport institutions. Therefore further insights are needed into how gay sport may be abandoning its queerness in order to seek acceptance and legitimization by wider sport institutions. What can be done about queer participation in mainstream sports?

\section{References}

Adams, A. and Anderson E. (2012) Exploring the relationship between homosexuality and sport among the teammates of a small, Midwestern Catholic college soccer team. Sport, Education and Society, 17(3): 347-363.

Adriaanse, J.A. and Claringbould, I. (2014) Gender equality in sport leadership: from the Brighton declaration to the Sydney scoreboard. International Review for the Sociology of Sport, 1-20. DOI: 10.1177/1012690214548493.

Allain K.A. (2008) Real fast and tough: the construction of Canadian hockey masculinity. Sociology of Sport Journal, 25(4): 462-481.

Amnesty International (2014) Russia: legacy of Olympic Games tarnished by arrests. Available at: http://www.amnesty.org/en/news/russia-legacy-olympic-games-tarnished-arrests-2014-02-22

(Accessed 22 July 2014).

Anderson-Minshall, D. (2013) Nike wants to sponsor first major pro athlete - who is going to lead the way? The Advocate. Available at http://www.advocate.com/sports/2013/04/15/nike-wantssponsor-first-major-out-pro-gay-athlete (accessed 2 October 2014).

Anderson, E. (2009) Inclusive Masculinity: The Changing Nature of Masculinities. New York: Routledge.

Anderson, E. (2011a) Masculinities and sexualities in sport and physical cultures: three decades of evolving research. Journal of Homosexuality, 58: 565-575.

Anderson, E. (2011b) Gay athletes, straight teams, and coming out in educationally based sport teams. Gender \& Society, 25(2): 250-268.

BBC (2012) Nepal hosts South Asia's first gay sports tournament. Available at: http://www.bbc.co.uk/news/world-asia-19929010 (accessed 30 September 2014).

Beasley, C. (2008) Rethinking hegemonic masculinity in a globalizing world. Men and Masculinities, 11(1): 86-103.

Bernstein, A. (2002) Is it time for a victory lap? Changes in the media coverage of women in sport. International Review for the Sociology of Sport, 37(3-4): 415-428.

Boren, C. (2013) Obama names openly gay athletes to Sochi Olympic delegation. The Washington Post. Available at: http://www.washingtonpost.com/blogs/early-lead/wp/2013/12/18/obama-namesopenly-gay-athletes-to-sochi-olympic-delegation/ (Accessed 10 December 2014). 
Broad, K. L. (2001) The gendered unapologetic: queer resistance in women's sport. Sociology of Sport Journal, 18(2): 181-204.

Bruce, T. (2012) Reflections on communication and sport: on women and femininities. Communication \& Sport. 1(1/2): 125-137.

Butler, J. (1990) Gender Trouble: Feminism and the Subversion of Identity. London: Routledge.

Cashmore, E. and Cleland, J. (2012) Fans, homophobia and masculinities in association football: evidence of a more inclusive environment. The British Journal of Sociology, 63(2): 370-387.

Caspari, L. and Fritsch, O. (2014) Merkel lobt Hitzlspergers Coming-out. Die Zeit. Available at: http://www.zeit.de/gesellschaft/zeitgeschehen/2014-01/hitzlsperger-reaktionen-westerwellezwanziger (accessed 6 October 2014).

Caudwell, J. (ed.) (2006) Sport, sexualities and queer/theory. London: Routledge.

Caudwell, J. (2011) Does your boyfriend know you're here? The spatiality of homophobia in men's football culture in the UK. Leisure Studies, 30(2): 123-138.

Clayton, B. and Harris, J. (2009) 'Sport and metrosexual identity: sports media and emergent sexualities’. In J. Harris and A. Parker (eds.) Sport and Social Identities. Basingstoke: Palgrave Macmillan, pp. 132-149.

Connell R. (1990) 'An iron man: the body and some contradictions of hegemonic masculinity.' In M. Messner and D. Sabo D (eds.) Sport, Men and the Gender Order. Champaign, IL.: Human Kinetics, pp. 83-114.

Connell, R. (1995) Masculinities. Berkeley: University of California Press.

Connell, R. (2009) Gender. Cambridge: Polity Press.

Connell, R. (2014) Masculinity, coloniality, hegemony: trajectories of research and politics. Keynote Address. Dislocating Masculinity Revisited Symposium. School of Global Studies, University of Sussex. 4 July 2014.

Cooky, C. Messner, M.A. and Hextrum, R.H. (2013) Women play sport, but not on TV: a longitudinal study of televised news media. Communication \& Sport, 1(3): 203-230.

Dashper, K. (2012) Dressage is full of queens!' Masculinity, sexuality and equestrian sport. Sociology, 46(6): 1-16.

Davidson, J. (2006) 'The necessity of queer shame for gay pride: The Gay Games and Cultural Events'. In J. Caudwell (ed.) Sport, sexualities and queer/theory. London: Routledge, pp. 90-105.

Davidson, J. (2013) Sporting homonationalisms: sexual exceptionalism, queer privilege, and the $21^{\text {st }}$ century international lesbian and gay sport movement. Sociology of Sport Journal, 30: 57-82.

Davidson, J. (2014) Racism against the abnormal? The twentieth century Gay Games, biopower and the emergence of homonational sport. Leisure Studies, 33(4): 357-378.

Elling A., Knoppers, A. and de Knop, P. (2003) Gay/lesbian sport clubs and events: places of homosocial bonding and cultural resistance? International Review for the Sociology of Sport, 38: 441-456.

FGG (2014a) Mission, vision and values. Available at: http://www.gaygames.net/index.php?id=56 (accessed 18 September 2014).

FGG (2014b) History of the FGG and the Gay Games. Available at: http://www.gaygames.net/index.php?id=28 (accessed 18 September 2014). 
Gallagher, S. (2014) Thomas Hitzlsperger. Daily Mail. Available at: http://www.dailymail.co.uk/sport/football/article-2747813/Thomas-Hitzlsperger-It-impossiblecome-gay-I-player-attention.html\#ixzz3EnNxqb2p (accessed 30 September 2014).

Gay and Lesbian Tennis Alliance (2014) General info. Available at: http://glta.net/general-info (accessed 30 September 2014).

Gilbert, D. (2014) Interview with David Gilbert, President and CEO of Positively Cleveland (Cleveland Convention and Visitor Bureau). 14 August 2014.

Griffin, P. (2011) Some thoughts on straight allies in sport. Available at: http://ittakesateam.blogspot.com/2011/06/some-thoughts-on-straight-allies-in.html (Accessed 13 June 2011).

The Guardian (2009) World Outgames 2009. Available at: http://www.theguardian.com/world/gallery/2009/jul/27/gay-rights-denmark (accessed 30 September 2014).

Hargreaves, J. A. (2000) Heroines of Sport: The Politics of Difference and Identity. London: Routledge.

Harris, P. (2014) Interview with Phyllis Harris, Executive Director, The LGBT Community Center of Greater Cleveland. 6 August 2014.

Hirose, A. and Pih, KK-h. (2010) Men who strike and men who submit: hegemonic and marginalized masculinities in mixed martial arts. Men and Masculinities, 13(2): 190-209.

Howson, R. (2006) Challenging hegemonic masculinity. London: Routledge.

Jarvis, N. (2002) Sponsorship and gay sport: a case study of the 2000 Gay Softball World Series. International Journal of Sports Marketing \& Sponsorship, 4(3): 205-230.

Jarvis, N. (2006) The Meaning of Sport in the Lives of Gay Men. Ph.D. Thesis, University of Brighton, U.K.

Jarvis, N. (2013a) A short selective history of the Gay Games: conflicts, clashes and controversies. In U. Merkel (ed.) Power, politics and international events: socio-cultural analyses of festivals and spectacles. Routledge Advances in Event Research Series. Abingdon, UK: Routledge, pp. 85-102.

Jarvis, N. (2013b) The inclusive masculinities of heterosexual men within UK gay sport clubs, International Review for the Sociology of Sport, 0(0): 1-18. DOI: 10.1177/1012690213482481

Jones, L. and McCarthy, M. (2010) Mapping the landscape of gay men’s football. Leisure Studies, 29(2): 161-173.

Kian, E.M., Anderson, E., Vincent, J. and Murray, M. (2013) Sport journalists’ views on gay men in sport, society and within sport media. International Review for the Sociology of Sport, 1-17. DOI: $10.1177 / 1012690213504101$

Krane, V. (1996) Sport psychology lesbians in sport: toward acknowledgement, understanding and theory. Journal of Sport \& Exercise Psychology, 18(3): 237-246.

Krane, V. (2001) We can be athletic and feminine, but do we want to? Challenging hegemonic femininity in women's sport. Quest, 53(1): 115-133.

King, C.R., Leonard, D.J. and Kusz, K.W. (2007) White power and sport: an introduction. Journal of Sport \& Social Issues, 31(3): 3-1. 
Laurendeau, J. (2004) The Crack Choir and the Cock Chorus: the intersection of gender and sexuality in skydiving texts. Sociology of Sport Journal, 21(4): 397-417.

Leedy, G. and Connolly, C. (2007) Out in the cowboy state: A look at lesbian and gay lives in Wyoming. Journal of Gay and Lesbian Social Services, 19: 19-34.

Lenskyj, H. (1991) Combating homophobia in sport and physical education. Sociology of Sport Journal, 8(1): 61-69.

Majendie, M. (2013) 'We are normal Russians': pole vaulter, Yelena Isinbayeva defends anti-gay laws. The Independent. Available at: http://www.independent.co.uk/news/world/europe/we-arenormal-russians-pole-vaulter-yelena-isinbayeva-defends-antigay-laws-8764393.html (Accessed 10 December 2014).

McCormack M. (2011) Hierarchy without hegemony: locating boys in an inclusive masculinity setting. Sociological Perspectives, 54(1): 83-101.

McCormack M. (2012) The Declining Significance of Homophobia. Oxford: University Press.

McClymont, K. and Bagshaw, E. (2014) Ian Thorpe. Available at: http://www.watoday.com.au/sport/swimming/ian-thorpe-considered-coming-out-before-2000olympics-20140713-zt65z.html (accessed 30 September 2014).

McKay, J., Messner, M. and Sabo, D. (eds.) (2000) Masculinities, Gender Relations, and Sport. London: Sage.

Messner, M. (1992) Power at Play: Sports and the Problem of Masculinity. Boston: Beacon Press.

Miller, T. (2001) Sportsex. Philadelphia: Temple University Press.

Pronger, B. (1990) The Arena of Masculinity. Toronto: University of Toronto Press.

Pronger, B. (2000) 'Homosexuality and sport: who’s winning?' In J. McKay, M. Messner and D. Sabo D (eds.) Masculinities, Gender Relations, and Sport. London: Sage Publications, pp. 222-244.

The Sporting News (2014) WNBA to recruit gay fans to games, market to LGBT community. Available at: http://www.sportingnews.com/nba/story/2014-05-21/wnba-gay-community-campaignbisexual-homosexual-lgbt-effort-marketing-fans-brittney-griner-players-teams (accessed 2 October 2014).

Suchman, M.C. (1995) Managing legitimacy: strategic and institutional approaches. Academy of Management Review, 20(3): 571-610.

Sykes, H. (2006) 'Queering theories of sexuality in sport studies', in J. Caudwell (ed.) Sport, sexualities and queer/theory. London: Routledge, pp. 13-32.

Symons, C. (2010) The Gay Games: A History. London: Routledge.

Theberge N. (1995) Gender, sport and the construction of community. Sociology of Sport Journal, 12(4): 389-402.

Theberge N. (2000) 'Gender and Sport'. In J. Coakley and E. Dunning (eds.) Handbook of Sports Studies. London: Sage Publications, pp: 322-333.

Walker, S. (2014) Vladimir Putin: gay people at Winter Olympics must leave children alone. The Guardian. Available at: http://www.theguardian.com/world/2014/jan/17/vladimir-putin-gay-winterolympics-children (accessed 10 December 2014). 
Warner, D. N. (2004) Towards a queer research methodology. Qualitative Research in Psychology, 1(4): 321-337.

Weinke, C. and Hill, G.J. (2013) Does place of residence matter? Rural-urban differences and the well-being of gay men and lesbians. Journal of Homosexuality, 60(9): 1256-1279.

Wellard, I. (2002) Men, sport, body performance and the maintenance of 'exclusive masculinity'. Leisure Studies, 21: 235-247.

Williams, R. (1961) The Long Revolution. Harmondsworth: Penguin.

Wright, J. and Clarke, G. (1999) Sport, the media and the construction of compulsory heterosexuality: a case study of women's rugby union. International Review for the Sociology of Sport, 34(3): 227243. 